\title{
LA SOCIOLOGIA A BARCELONA, ELS ANYS SEIXANTA, DES DEL MEU RECORD PERSONAL*
}

\author{
Juli Busquets \\ Catedràtic de Sociologia de la UAB
}

\section{ANTECEDENTS: S'HAVIA D'ESTUDIAR A MADRID}

Després de la guerra civil, i durant molts anys, l'ensenyament a Espanya va continuar organitzat d'acord amb la reforma que va fer Moyano, ministre de Narváez, el 1857, ja que els successius intents de reformes havien estat avortats per la reacció. I la llei Moyano es va fer seguint el model francès, anomenat napoleònic, centralizzat i jerarquitzat, on tot era planejat i decidit al Ministeri, a Madrid.

Per l'ensenyament universitari, el territori estava dividit en dotze «districtes universitaris» encapçalats per una universitat, i només una, governada per un rector que, a més a més, en els períodes autoritaris no era elegit, sinó nomenat pel Ministre d'Educació. Quasi totes les universitats tenien la mateixa estructura: les cinc facultats clàssiques: Lletres, Ciències, Dret, Medicina i Farmàcia. Les universitats politècniques no existien, $i$ algunes de les escoles tècniques on s'estudiaven les enginyeries no depenien del ministre d'Educació, sinó del seu ministre respectiu (Obres Públiques, Indústria, Agricultura, etc.). Obviament, les facultats de Ciències de la Informació, Econòmiques, Polítiques, Sociologia, etc. no existien.

El 1944 es va crear la Facultat de Ciències Polítiques de Madrid, segons sembla amb la intenció inconfessada de proveir l'administració de l'Estat de quadres

* Aquest treball, tal com diu el títol, l'he escrit ades del meu record personal". Aixi, doncs, ni és ni pretén ser un treball històric. I com que està escrit des del meu record personal, amb tota seguretat que hi manquen noms de persones que van fer molt per la sociologia i hi haurien de ser citades, però que malauradament jo no les vaig conèixer, i a les quals demano disculpes per l'omissió involuntària. Aquest treball només precén ser material perquè el dia de demá el pugui urilitzar algú que escrigui, ja amb rigor històric, alguns esdeveniments, que cada vegada són més llunyans i que, a poc a poc, se'ns esborren de la memòria.

Per últim, vull fer notar que aquest relat acaba amb els esdeveniments ocorreguts al campus de Betlaterra entre el febrer $\mathrm{i}$ el juny de 1975: la vaga general i la declaració de Bellaterra aprovada al claustre, i que, per zant, tots els fets posteriors no hi són esmentats, com tampoc les pexsones que van arribar a la UAB després d'aquelles dates. 
la formació dels quals no estigués basada en l'estudi de la llei, del Dret, contrari a la dictadura per se, sinó en l'estudi de "la realitat" --deien ells - analitzada segons l'Economia, la Sociologia i la Politologia. El que va passar va ser tot el contrari del que el govern s'havia proposar: L'estudi d'aquestes noves ciències va ajudar els estudiants a prendre consciència política, encara més de pressa que el Dret, $\mathrm{i}$ a finals del cinquanta. la facultat ja era un centre d'agitació. ${ }^{1}$

Però el fet és que es va crear una facultat on es podia aprendre quelcom de sociologia, sembiant, o potser encara una mica més precari, pero no gaire, al que passava a la UAB, entre el 1970 i el 1986, quan la Sociologia només era una especialitat d'Econòmiques. Així, doncs, durant molts anys, els que voliem cstudiar-ne i per diverses causes (econòmiques, polítiques, familiars, etc.) no podím anar a l'estranger, no teniem altre camí que el precari de la facultat de Polítiques de Madrid. Allà n'ensenyaven els catedràtics ${ }^{2}$ Manuel Lissarrague (1910-65) i Enrique Gómez Arboleya (1919-59), probablement el millor dels sociòlegs espanyols que no es van exiliar després de la guerra civil. Els ajudants eren joves de la generació següent, la que no va participar a la guerra civil, com Salustiano del Campo, González Seara, Enrique Martín López, Alejandro Muñoz Alonso, etc. que són, des de ja fa molts anys, catedràtics.

Al mateix temps que es creava la facultat de Polítiques i Econòmiques de Madrid, es van crear, a Barcelona i a Bilbao, facultats, només d'Econòmiques, però que dins el seu pla d'estudis establien una sociologia obligatòria per als alumnes de primer curs. A la facultat de Barcelona es feren càrrec d'aquesta assignatura, inicialment el pare Alcorta, que era el catedràtic d'Ėrica i Sociologia de Lletres, i posteriorment Emili Boix ${ }^{3}$.

A les facultats de Lletres de Barcelona, València i Madrid, existien càtedres d'Ética i Sociologia ${ }^{4}$, però que de facto eren més d'Ética que de Sociologia; i

1. Aleshorcs, la Facultar es trobava dintre de la ciutat, a «el viejo caserón de la calle San Bernardon, i com que les assemblees i vagues que allí es feien eren molt visibles, els alumnes van convertir fa fácultat en un centre d'agitació política.

2. La Ciència Política i el Dret Conscitucional —que aleshores s'ensenyaven sota el títol dc "Teoria de l'Fstar" pel fer que el de "Drer Polític", com ja he dit, resultava subversiu al règimtenien com a catedràtics Carlos Oilero i Fraga Iribarne. El professor de Geografia Humana era Manuel Teran (sogre de Juan Linz), i els d'História eren José Antonio Maravall (parc del sociöleg ex-ministre José Maria), Valdeavelkano (que abans havia estat professor de la Universitat de Barcelona durant molts anys) i Díez del Corral. Entre els juristes destacaven: Truyol Serra, Garrido Falla, Rodrigo Uria, Alonso Olea, etc. En resum, un conjunt d'acadèmics de prestigi.

3. El 1965 va publicar un dels primers llibres de Sociologia escrits en caralà: Consideracions sobre lobjecte de la Sociologia.

4. El primer caredratic de Sociologia d'Espanya va ser Manuel Sales i Ferré (1843-1910), a la Facultat de Lletres de la Universizat de Madrid, si bé sembla que fonamentalment impartia cursos de Sociologia, per fer el doctorat. El 1899 va fundar l'Instituto de Sociología i cntre 1899 i 1904 va publicar un Tratado de Sociologia, de quatre volums, que va ser l'obra que el va donar a conèixer. Inicialment va estar lligar al pensarnent krausisca. És considerar el primer sociòleg carala. 
en les quals, malgrat alguna excepció notòria, com López Aranguren's s'exposava una concepció de l'ètica, més que conservadora, simplement antiquada i lligada a l'escolàstica.

\section{LA SOCIOLOGLA EMPIRICA}

Cap el 1960 es van treure a oposició les càtedres de Sociologia de les facultats d'Econòmiques de Barcelona i Bilbao, i les van guanyar Salustiano del Campo i Jiménez Blanco. Salustiano del Campo havia estudiat a la Universitat de Xicago, practicava l'empirisme anglo-saxó i va donar un cert impuls a la sociologia a Barcelona. Va conservar Boix com a adjunt i va reunir un petit grup de sociòlegs a la càtedra, als quals va intencar inculcat l'empirisme. I com que havia estat professor meu a Madrid, en acabar la carrera vaig poder entrar com ajudant de classes pràctiques, juntament amb Ricardo Moragas, Jaime Lanaspa, Julio Hardison, Josep Balcells, etc.

El 1966, Del Campo va fer dues aportacions importants a la Sociologia barcelonina: La col-lecció "Demos» de Sociologia de l'editorial Ariel, i la revista Anales de Sociologia del CSIC. A "Demos" es van publicar Elobrero y la ciudad de Pere Negre (1968), La innovación religiosa de Joan Estruch (1972), El medio rural en Andalucía de Miguel Siguan (1972) i el meu llibre El militar de carrera (1967), (que, dit sigui entre parèntesi, va ser segrestat, i a mi, per escriure'l, em van processar). Un any abans, a la col.lecció «Demos" de Ciència Política, s'havia publicat la Historia del pensamiento social de Salvador Giner.

La revista semestral Anales de Sociologia, va publicar tres números amb col-laboracions dels sociòlegs que s'acaben d'esmentar i d'Antoni Jutglar, Rogelio Duocastella, Ramón Bayés, i els geògrafs Josep Iglésies i Jaime Alzina. El 1967 Del Campo es va traslladar a la Universitat de Madrid i la revista aviat es va deixar de publicar ${ }^{6}$.

A Del Campo el va succeir en la càtedra Enrique Martín López, que va ser catedràtic a Barcelona, del seixanta-set al setanta-sis. Era deixeble de Lis-

5. En els anys cinquanta i duranr el periode d'obercura que va protagonitzar Ruiz Jiménez quan era ministre d'Educació, es va treure a oposició la càtedra d'Ética i Sociologia de la Universitat de Madrid, i s'hi van presentar López Aranguren i el dominic Todolí. López Aranguren va guanyar la càtedra, però cap al 1966 va ser separat del cos de catedràtics per raons polítiques. A Barcelona, l'expulsió d'Aranguren va provocar la dimissió en solidarirar del catedràric d'Estètica, Valverde, que li va cnviar un ancologic telegrama on deia: «No hay Estécica sin Ética. Apaga $y$ vámonos."

6. La col-lecció "Demos" i la revissa Anales, van comptar amb aportacions de Maravall, González Seara, Diez Nicolás, Amando de Miguel, Juan Linz, Carlos Moya, José Castillo, Torregrosa i Manuel Ramírez. 
"Papers»: Revista de Sociologia

sarrague i feia una sociologia diferent de la del catedràtic anterior. No obstant això, va mantenir l'anterior equip i amb ell s'hi van incorporar professors nous: Frederic Munné, Luis Vila, José M. Alsina, Emilio Rodríguez Lara, Eugeni Sabaré i més tard Carlota Solé i $M$. Teresa Benavent.

\section{LA SOCIOLOGIA FORA DE LA UNIVERSITAT}

El 1951, el Bisbat de Barcelona va crear l'ICESB (Institut Catòlic d'Estudis Socials de Barcelona), dirigit per Joan A. Ventosa i Emili Boix. El 1966 l'ICESB va organitzar una Escola de Ciències Socials. Simultàniament, un grup d'intel.lectuals demòcrates va crear EISA, paral.lela a la més coneguda escola de Madrid, CEISA, i que, com ella, renia la seva cobertura jurídica i base financera en una petita societat anònima. Desgraciadament les dues escoles de Barcelona, la de l'ICESB i EISA, patien certa precarietat econòmica, que dificultava una justa retribució del professorat, la gratuïtat de l'ensenyament, la creació d'una bona biblioteca, etc., $\mathrm{i}$ això les dugué a fer un intent d'unificació l'estiu del seixanta-set.

Un altre centre de Sociologia que, com I'YCESB, tenia un cert grau de dependència de l'Església era IPSA (Instituto de Sociología Pastoral Aplicada), dirigit pel pare Duocastella, que ja a mitjans dels anys cinquanta va publicar estudis sobre el comportament religiós a Mataró. A IPSA es va crear un equip d'cspecialistes en sociologia religiosa, que va rebre un cert reconeixement internacional, quan l'any 1965 es va celebrar a Barcelona la $8 \mathrm{a}$. Conferència Internacional de Sociologia Religiosa.

El 1969 es va crear la Fundació Jaume Bofill per realitzar investigacions sociològiques, fonamentalment sobre Catalunya, i ajudar, mitjançant la concessió de beques, postgraus universitaris. Molts dels actuals sociòlegs adults es van beneficiar del seu ajur durant els últims anys de la dictadura. Aquesta Fundació probablement va ser la més progressista de totes les interessades en sociologia. El seu director en certa ocasió va comentar: "Nosaltres som l'única Fundacio d'Espanya que ha estat escorcollada per la policia de Franco"'?

Dos altres centres d'investigació sociològica d'aquells anys, que també treballaven amb serietat científica, eren, el CEDEC, que, malgrat estar mancat de tota ajuda oficial o eclesiàstica, ha merescut ser qualificat per Salvador Gi$n^{8}{ }^{8}$ de "protagonista de la introducció de la Sociologia Moderna de Catalunya», i l'IEL, Institut d'Estudis Laborals d'ESADE, dedicat especialment a la

7. IeSÚs de Migued, MÉlisSA G. MoYer: Sociology in Spain. Curtent Sociology. Vol. 27. 1, 1977. Sage Publicacions. Pag.73.

8. Salvador Giner: Sociología en España. CSIC, Madrid, 1990, p.54. 
Sociologia del Treball. Allà hi treballaven fonamentalment dos "tàndems": Alfonso Carlos Comín, amb el seu partenaire Juan Nepomuceno García Nieto i, per altra part, Jordi Estivill amb Igansi Pons. El centre va patir tambe els avatars de la repressió: durant l'estat d'excepció, Comín va anar a la presó Model i el pare García Nieto va ser tancat en un convent de Manresa.

Per últim, el 1963 es va crear a Barcelona un centre que, com molts de Madrid gaudia d'una certa protecció oficial: L'Institut de Ciències Socials de la Diputació, que dirigia Jordi Xifra, i que va donar vida a una revista i posteriorment a una Escola de Sociologia. Cal dir que Xifra, més enllà del seu tarannà conservador, deixava fer, i a la seva revista hi vam poder publicar aquells que no compartíem les seves idees, i a l'Escola vam impartir classes, entre d'altres, Antoni Jutglar, Fernández Buey i jo mateix. L'Institut, amb l'arribada de la democràcia, es va reconvertir políticament i acadèmicament: políticament per raons òbvies i acadèmicament perquè va passar de ser un centre de Sociologia a ser-ho de Politologia. Des d'aleshores el dirigeix Isidre Molas.

\section{UN INTENT NON NATO D'ASSOCIACIO CATALANA DE SOCIOLOGIA}

EI 1966 es va celebrar a Evian (França) el Gè Congrés Mundial de Sociologia i allà ens vam conèixer alguns sociòlegs catalans. Recordo que hi van assitir "Pancho" Marsal, Salvador Giner, Antoni Güell, etc.

De retorn vam fer algunes reunions, inicialment a casa d'Àngels Pascual, per comentar el congrés, i posteriorment a casa meva, en un frustrat intent de crear una associació catalana de sociologia. Van assistir-hi alguns professors de la càtedra de la facultat d'Económiques (Boix, Moragas, Hardison, etc.) i d'altres de la resta de la ciutat, entre els quals recordo Ramon Bayés, Joaquim Maluquer, el pare Duocastella, Alfonso Carlos Comín i em sembla que Carreño.

A finals de la dècada dels seixanta es van publicar alguns treballs on es relacionaven els noms dels que aleshores ens dedicàvem a la sociologia a Barcelona ${ }^{2}$, i que davant el problema de la inexistència d'una carrera de sociologia, teníem diverses procedències:

9. ViCEnta Jose SAstre Garcia: Las Ciencias Sociales en España. Universidad de Comillas, Madrid, 1971. En aquest llibre s'hi citen trenta-dos sociòlegs catalans (en el llibre diu ude la región noreseen).

Sociologia Española de los años 70, Confederación de las Cajas de Ahorros, Madrid, 1971. Se'n relacionen vint-i-dos. És més rigorosa.

GUY HFRMET: uLa sociologia empírica en Españan, Anales de Sociología, núm. 4-5, CSIC, Barcelona, 1968. En relaciona vinc persones. 
Uns havien estudiat distintes carreres a Barcelona, fonamentalment Dret $^{10}$, com Emili Boix (1917), Luís Carreño (1933) o Ricardo Moragas (1935), però a vegades fins i tot carreres tècniques, enginyeries, com Alfonso Carlos Comín (1933), o Ramón Bayés (1930). Altres, com ja he dit abans, havíem anat a Madrid a estudiar Ciències Polítiques, com Jordi Xifra (1928), Josep Balcells (1923) o jo mateix (1932), etc.

Un tercer grup de sociòlegs d'aquella època havia arribat a la sociologia com a conseqüència de l'evolució d'una inquietud social, que tenia un origen religiós ${ }^{11}$, i molt sovint havia estudiat en universitats més o menys lligades a l'Església: a Lovaina hi estudià Francisco Isern; a la Universitat Loiola de Chicago, Pere Negre, i Daniel Cervera (1924); a París, Xavier Adroer (193i); a la Gregoriana de Roma, Rogelio Duocastella (1914) i Antoni Güell (1937); a Londres, García Nieto (1929), i en aquest grup s'hi podien incloure alguns sociòlegs de l'educació, com Octavi Fullat (1928). Va ser quelcom freqüent a la meva generació, i aquesta és encara l'última arrel de l'origen vocacional d'alguns dels sociòlegs de certa edat.

Un quart grup havia estudiat en universitats estrangeres i alguns s'hi van quedar a ensenyar: Juan Francisco Marsal (1928), fill d'un emigrant a l'Argentina, era professor de la universitat El Salvador de Buenos Aires i dirigia la Revista Latinoamericana de Sociologia de l'Instituto Torcuato di Tella; Salvador Giner (1934) era professor a Reading, on estudiava Carlota Solé (1944); Esteban Pinilla de las Heras (1926) treballava a la Universitat de París, i en aquest àmbit cultural francòfon s'havien format, o aleshores ho estaven fent, Joaquim Maluquer (1930) a Ginebra; Joan Estruch (1943) a Lovaina, i a París

Quan el 1968 es va produir el maig francès i la reforma de Villar, vaig publicar uns articles al diari El Correo Catalán on defensava la conventència de crear una carrera de sociologia. En un donava una relació dels noms dels que aleshores ens dedicàvem a la sociologia a Barcelona. En general els noms que hi ha aquí coincideixen amb els avançats a l'article esmentat.

10. En els anys scixanta, l'orientació d'estudiosos procedents del Drer, cap a la Sociologia, no tenia a Barcelona la solcra d'altres universitats, per exemple la de Granada, on Murillo Ferrol dirigia un seminari de Sociologia Política, a la facultat de Dret. No obstant això, pocs anys després, es van començar a fer a Barcelona estudis de Sociologia Electoral cada vegada més imporeants, destacanr-hi noms com Isidre Molas, Josep M. Vallès, avui Rector de la UAB, Rosa Virós, etc.

Per altra banda, en aquells anys, es va començat a desenvolupar a la nosera ciutat la sociolinguística, generalment per persones que procedien del món de la flologia, com Badia Margarit, que aleshores era Rector de la Universitar de Barcelona, Aracil, Vallverdí, Ninyoles, els quals el 1974 van participar al 8è Congrés Mundial de Sociologia, a Toronto.

11. El nombre de sociòlegs que havien estat clergues els anys seixanta era molt elevat. Jesús de Miguel, a la citada Sociology in Spain n'assenyala un $12 \%$ (nota 27). peró crec que la xifra era més alta. Al número 3 de "Anales de Sociología" José Cazorla publicà una relació de "Estudios empiricos de Sociologían, fets des de 1949 ins a 1967 i quasi la meitat eren de Sociologia religiosa. Tors els escudis de "Sociologia de la Sociologia" fers aquells anys, ressalten la gran quanticat de sociòlegs que van arribar a la professió per evolució de la seva inquietud tcligiosá. 
La sociologia a Barcelona, els anys seixanta, des del meu record personal

Angels Pascual (1937), Marina Subirats (1944) i, una mica més tard, Sergio Vilar, que es va haver d'exiliar després de publicar La oposición en España.

Per últim, a la llista s'hi podrien afegir professors de ciències socials afins, que en aquella època a vegades eren considerats sociòlegs, com l'historiador Antoni Jutglar (1933), l'antropòleg Claudio Esteva (1918), el psicòleg Miguel Siguan (1918), etc. ${ }^{12}$.

\section{LA REFORMA DE VILLAR I LA CREACIO DE L'AUTOONOMA}

Per altra banda, el país seguia el seu curs: El març del seixanta-vuit va dimitir el ministre d'Educació Lora Tamayo i al seu lloc va ser nomenat un tecnòcrata brillant, que deien que era proper a l'Opus Dei: José Luis Villar Palasí, el qual va prendre possessió del càrrec el 17 d'abril, amb estat d'excepcio i cinc universitats tancades. I el mes seguient va esclatar el maig francès. Suposo que aquests fets el van ajudar, enfront d'un govern gens innovador, a tirar endavant la seva reforma: la Ley General de Educación y Financiamiento de la Reforma Educativa, aprovada finalment l'estiu del setanta. Pero abans havia ja creat les tres universitats autònomes ${ }^{13}$, una de les quals va ser la de Bellaterra, de la qual seria el primer Rector el seu germà Vicente.

La reforma que va engegar fou important, perquè, com ja s'ha dit en línies generals, es continuava vivint de la Llei Moyano. La reforma de Villar va allargar l'ensenyament primari fins a un total de vuit anys (des dels sis fins als catorze) i simultàniament va escurçar el batxillerat a dos anys (que finalment van ser tres), amb la qual cosa la Universitat quedava molt més a prop de la majoria dels ciutadans, que només estudiaven la primària. I a més a més va obrir les portes a la població adulta mancada de titulació a través del CAU (Curs d'Adaptació Universitària).

En l'àmbit universitari va ser fonamental la creació de les tres universitats autònomes, de les quals la de Barcelona/Bellaterra va ser d'avantguarda, potser perquè les condicions objectives de Catalunya hi ajudaven, o potser per la peculiar procedència d'un professorat elegit entre els antics membres de la Universitat Autònoma de la República (Calsamiglia, Casanoves, etc.) i entre els seixanta-nou PNN (professors no-numeraris) que el rector Valdecasas havia

12. La relació, evidentment, ni pretén ni pot ser exhaustiva, a més tenint en compre els difusos límits de la sociologia. Per exemple: Guy Hermet, entre els treballs de sociologia empirica, en cinta,i el qualifica d' "excel-lencw, un de M. Aurèlia Capmany (que no sol ser inclosa en aquestes relacions) sobre La dona a Catalunya, esrudi empíric de cent vint dones fet el 1966.

13. El Decret-Llei de 6 de juny del 68, crea la UAB, i el Decrer $774 / 68$ de 27 de juliol el desenvolupa, disposant que la UAB consti de quarre faculrats: Lletres, Ciencies, Medicina i Economiques. 
expulsat pocs anys abans per raons politiques. Aquests professors, que van ser el nucli central de la UAB (Jutglar, Termes, Fontana, Izard, Daufi, Enric Lluch, els germans Molas, Paco Noy, etc.), eren persones actives políticament i n'hi havia molts que havien participat el 1966 a l'assemblea dels Caputxins de Sarrià (la capurxinada), on es va fundar el SDEUB o Sindicat Democràtic d'Estudiants ${ }^{14}$.

Per altra banda, les autoritats universitàries que van fundar la UAB van actuar amb un tarannà acadèmic obert, amb una linia diferent i fins i tot oposada al sectarisme polític predominant de l'època, que va fer possible l'existència d'un marc adequat per a la renovació. I aquí és obligat citar els germans Villar Palasí, Paco Noy, cervell i braç executiu del Rector, i Frederic Udina, entranyable degà de la Facultat de Lletres, primera de la UAB, on es va impartir una docència numèricament rellevant i que fou, des de la seva fundació, un centre d'autèntica conscienciació antifranquista.

\section{L'ESPERIT DE LA UAB}

El cas és que, per unes causes o unes altres, es creà una universitat diferent de les que aleshores existien a l'Estat, que intentava seguir el model anglo-saxó, obviant el vell model napoleònic, únic imperant aleshores a Espanya. I les diferències es van fer evidents en cinc aspectes: el professorat, l'activitat docent, els criteris d'avaluació, els plans d'estudi i l'estructura dels òrgans de govern de la Universitat.

1. El professorat: Es va intentar prescindir de l'antic "professor-numerari" que era -i és- un funcionari, i substituir les oposicions i concursos de trasliat, que eren les formes utilitzades aleshores per reclutar el professorat, pel "professor-contractat", que entrava a la UAB, fins i tot com a catedràtic, mitjançant un contracte que se li feia pel seu prestigi i mèrits. I això va permetre integrar-hi els professors "heterodoxes" abans citats, que difícilment podien aprovar les oposicions per la seva discrepància política.

Per valorar degudament aquesta innovació, cal tenir en compte la importància que aleshores tenien les oposicions, així com el centralisme que les caracteritzava. D'entrada es feien sempre a Madrid, cosa que implicava un desavantatge pel que vivia fora de la capital per les despeses (viatges, hotel, etc.) que havia de pagar; perquè no hi havia companys per anar a escoltar el

14. Una de les estudiants que va participar a la capucxinada és l'actual professora del departament de Sociologia de la UAB, Maria Pia Barenys, que aleshores era dirigene dels estudiants del sindicat a la faculrat de Dret. 
teu exercici; per les pressions que llavors es feien, òbviament a Madrid, i perquè hi havia un exercici en què era permès utilitzar qualsevol material de consulta que et podien portar de fora de l'aula (de casa teva) els teus col.legues. No cal dir que la majoria dels que treien les càtedres vivien a Madrid, i que, passat el minim de temps possible, tornaven a casa seva deixant de nou les càtedres anomenades "de provincias" buides.

No va ser així a la UAB. De l'escassa importància numèrica que els catedràtics numeraris van tenir els primers anys de la UAB, és indicatiu el fet que el curs 73-74, sis anys després de la seva fundació, a la Facultat de Dret només hi havia; quatre catedràtics numeraris; a les d'Econòmiques i Medicina, tres a cada una, i a la de Ciències de la Informació, només un.

2. L'activitat docent: Davant la docència centrada en la lliçó magistral del catedràtic, que impartia una única classe a cents d'estudiants, es va organitzar l'ensenyament dividint els alumnes en grups reduïts, amb la qual cosa la docència va passar de ser impartida per vells catedràtics ("vacas sagradas», amb un confortable status social) a estar en mans de joves PNN (Professors no-numeraris), "becerros desacralizados" i perseguits, que a més no consideràvem un descrèdit repetir la mateixa classe a tres grups (es van establir nou hores de docència obligatòria, tres hores a cada un dels tres grups).

3. Els criteris d'avaluació. En comptes de l'examen final, que era el criteri quasi universal de les antigues universitats, entre altres raons perquè la gran quantitat d'estudiants no feia possible una altra formula, es va decidir utilitzar l'avaluació continuada, fent múltiples proves durant el curs i qualificant l'alumne per la seva participació a la classe. Reconec que dels cinc punts que aquí assenyalo com a eixos d'aquell esperit inicial de la UAB, aquest és possiblement el primer que va fer fallida, entre altres coses perquè també a la nostra universitat el nombre d'alumnes ens va desbordar i les classes, en algunes facultats, aviat van arribar a tenir gairebé dos-cents alumnes.

4. Els plans d'estudi fins aleshores eren totalment rígids i tenien de cinc a set assignatures per curs, que per a cada carrera eren les mateixes a tot Espanya, i tots els alumnes les havien d'estudiar. A partir de la Reforma, i especialment a la UAB, els plans d'estudi van ser renovats d'acord amb el model anglo-saxó, mantenint-se algunes assignatures troncals però introduint-ne un gran nombre d'optatives. Per exemple, a la Facultat de Lletres es va suprimir l'obligatorietat, fins aleshores sacrosanta, del llatí i del grec, i s'hi introduiren assignatures "sospitoses" com la Sociologia i l'Economia. (Contràriament, a la Facultat de Medicina les optatives, encara ara, gairebé no existeixen). 
"Papers": Revista de Sociologia

5. Els òrgans de govern de la Universitat van passar a ser electius i democratitzats. Fins aleshores els claustres de Facultat i de la Universitat estaven formats per "tots" els catedràtics de la Facultat i "només" per ells, i els professors "adjunts" només assistien al claustre com a suplents en cas d'absència del catedràtic. A l'Autònoma, per contra, els claustres estaven formats per professors electes de tots els nivells, als quals aviat es van afegir estudiants, administratitus i fins i tot els laborants, i en aquells claustres democratitzats vam començar a elegir els nostres degans i, més tard, el nostre rector.

\section{LA SOCIOLOGLA A LA FACULTAT DE LLETRES (1968-70)}

Reprenem el fil i tornem a la Sociologia. Creada la UAB el 68 , es va decidir iniciar a l'octubre un primer curs de Lletres en unes aules annexes al monestir de Sant Cugat, i entre les matèries optatives d'aquell primer any hi figurava una assignatura de Sociologia de la qual era professor Ricardo Moragas i amb qui col.laborava Jaime Lanaspa.

El curs següent, 69-70, va ingressar a la Facultat de Lletres Antoni Jutglar, historiador social, que aleshores semblava orientar-se vers la sociologia i tenia al seu càrrec una "Iniciació a les Ciències Socials». Durant aquell curs es va crear un departament de Ciències Socials, on, a més dels sociòlegs ja citats, s'hi van integrar els geògrafs Enric Lluch i Dolors Garcia Ramon, que sempre van fer una geografia humana molt propera a la sociologia, i Jutglar va plantejar la possibilirat d'organitzar un segon cicle d'estudis de Ciències Socials.

L'estiu del setanta, i quan ja feia sis anys que era professor a l'antiga facultat d'Econòmiques, Frederic Udina i Jordi Nadal em van cridar a la UAB, i després d'analitzar el meu currículum i fer-me una entrevista, em van contractar com a "agregat". En començar el curs 70-7I teníem assignatures de Sociologia Jutglar, Moragas i jo. Però Moragas i Jutglar van deixar la UAB durant el curs, i simultàniament van entrar al Departament Joan Estruch, Antoni Tulla, Àngels Pascual i Mary Carmen Martínez. Tors continuen essent professors de la UAB, encara que en altres disciplines, excepte Estruch, és clar.

\section{EL TRASLLAT A LA FACULTAT D'ECONÒMIQUES}

La creació d'una carrera de Sociologia en una facultat de Lletres és assumible, $i$ en diverses universitats nord-americanes ja s'estudiava conjuntament Sociologia, Antropologia i Psicologia Social a la mateixa facultat des de feia 
La sociologia a Batcelona, els anys seixanta, des del meu record personal

anys. Però a Espanya, el 1970, costava de comprendre, per la inèrcia creada per l'encotillament de la universitat napoleónica, i malgrat la ruptura que estaven iniciant les universitats autònomes.

En conseqüència, es va decidir nomenar una comissió de professors aliens a la universitat $i$, per tant, no implicats en les tensions internes (entre persones i entre facultats), perquè fessin un dictamen respecte a la ubicació de la facultat $i$ als seus plans d'estudi. I es va cridar tres sociòlegs catalans que havien assolit cert prestigi a l'estranger: Juan Francisco Marsal, que estava a Buenos Aires; Salvador Giner, a Reading, i Esteban Pinilla, a París; i s'hi va afegir Amando de Miguel. I van decidir que era millor la ubicació a la facultat d'Econòmiques, homologant, en aquest punt, la UAB amb les restants universitats espanyoles. Així es va fer i se'ls va oferir de quedar-se com a catedràtics contractats, cosa que van acceptar Marsal, de Miguel $i$, només inicialment, Pinilla.

A l'Anuari del curs 197 I-72 de la UAB, es feia esment només de cinc professors de Sociologia, tres a Econòmiques: Marsal, com a catedràtic, Estruch, com a agregat, i Oltra com a adjunt, i dos a Lletres, jo com a agregat i el pare Coloma, que tenja al seu càrrec les classes de Girona, com a adjunt.

El pas dels alumnes de Lletres que volien ser sociòlegs a la Facultat d'Econòmiques no va quedar exempt de dificultats, i dues alumnes que provenien de la primera promoció de Lletres (una era Carme Maltas) van haver de perdre un curs. Entre els que van passar n'hi va haver alguns que després van ser professors de la UAB, recordo José Luís Crespán, Josep Ramoneda, Salvador Alsius i Francesc Hernández.

Quan el 1973 es publicà el primer número de Papers, Crespán, que era aleshores alumne de la facultat d'Econòmiques, publicà un article on comentava que a les dues facultats d'Econòmiques, la de l'antiga Universitat de Barcelona $i$ la de la UAB, uels departaments de Sociologia (...) tenen problemes semblants (...) el que fa disminuir en forma exagerada les assignatures pròpiament sociologiques" ( $p .222$ ) i més endavant assenyala que a la UAB «les exigències dels economistes són encara més grans. Un alumne cursa tot un primer cicle, més de la meitat de la seva carrera, i ha estudiat durant tres anys quatre assignatures de Sociologia, i naturalment, en règim optatiu" (p. 223). En efecte, un any abans, a l'anuari del curs $71-72$, es recull l'horari de classes de la facultat d'Economiques: Al primer curs no hi ha res $i$ al segon només una Sociologia.

No obstant això, el departament va anar creixent. Aviat hi van entrar Adolfo Perinat $\mathrm{i}$ Àngels Pascual que, malgrat que ara són catedràtics de Psicologia i de Geografia respectivament, abans havien estat bastants anys lligats al nostre departament. L'any setanta-tres van entrar Faustino Miguélez, Marina Subirats, Ramon Bonal i Maria Pia Barenys, i fou també aleshores que hi va arribar Carlos Rama, dues vegades exiliat polític, primer de l'Uruguai i després de Xile. El 1975 hi van entrar Jesús de Miguel i Luis Lemkov, i el 1976 (i ja som 
fora del limit cronològic d'aquest article), la nostra degana Judit Astelarra; o sigui que del setanta-tres al setanta-sis hi van entrar vuit professors, tres dels quals, Miguélez, De Miguel i Subirats, són actualment catedràtics a les universitats de Barcelona. Mentrestant, la docència s'estenia també a la Faculrat de Ciències de la Informació, creant-se un departament ampli i nombrós: El 1977 el departament de Sociologia tenia setze professors i s'hi impartien noranta-tres hores de classe per setmana a un total de 2.357 estudiants.

Per altra banda, al departament de Pedagogia de Lletres, i després a l'Escola de Professors d'EGB, s'hi reuní un altre nucli de sociòlegs dedicats a la Sociologia de l'Educació, dels quals fou pioner Josep Pallach, fundador d'un dels partits soclalistes de Catalunya, el PSC-R (Reagrupament), qui va morir el 1977. En aquest àmbit ja hi treballaven també Masjoan, Quintana, Rosa Quillet, Eulàlia Calzada, etc.

\section{LA DECLARACIO DE BELLATERRA}

A finals dels anys seixanta, i sobretot a principis dels setanta, la lluita per la conquesta de la llibertat es generalitzà. El març de 1975, quan encara vivia Franco, a la UAB es va aprovar la "Declaració de Bellaterra", on es demanava un canvi democràtic a la Universitat. La "declaración va ser consequiència d'un llarg procés en què van participar molts professors, fonamentalment socialistes i comunistes, i va començar quasi un any abans, el maig del setanta-quatre, quan Enric Lluch, un líder carismàtic del professorat, va plantejar al claustre de la facultat de Lletres la conveniència de convocar un "Claustre General».

El quince de març del setanta-cinc es va reunir el Claustre i les propostes del grup renovador van ser aprovades d'una a una, segons consta a les actes: Els principis bàsics, defensat per Josep Laporte; la celebració d'un nou claustre per elegir Rector, defensat per josep Maria Vegara; la convocatòria d'un congrés universitari català, defensat per Borja de Riquer; la reobertura de la Universitat de Valladolid, defensat per l'alumne Jordi Degà, i el Manifest, defensat per Josep Montserrat Torrens, que aleshores era el cap del PSC a la UAB. El document titulat Per una societat nova en una societat democràtica, i popularment conegut com «declaració de Bellaterra», havia estat presentat per vint-i-vuit professors 15 .

15. El dia 18 de març de 1991, commemoració del quinzè aniversari del Manifest de Bellaterra, es va lliurar la Medalla de la UAB als següents impulsors i signants del manifest: Pilar Benejam, Muriel Casals, Enric Casassas, Felip Cid, Joan Clavera, Xavier Comas, Francesc Espiner, Helena Escalella, Eugeni Giral, Josep Grifoll, Rafael Jiménez de Parga, Joan Ramon Laporte, Enric Uluch, Isidre Molas, Joaquim Molas, Miquel Molins, Josep Montserrat, Miquel de Moragas, Jordi Nadal, Francesc Noy, Manuel Parés, Àngels Pascual, Borja de Riquer, Santiago Roldán, Ramon Segura, Narcís Serra, Eduardo Spagnolo i Josep M. Vergara. 
No ho puc explicar amb precisió, perquè personalment no vaig poder assistir al claustre. El febrer de 1975 vaig ser condemnat a mig any de presó i traslladat a una presó militar a Ceuta. Però els companys que se les enginyaven per fer-me arribar algunes missives, em van explicar que el mateix dia que el claustre de la UAB va aprovar la "declaració de Bellaterra" va votar també, després d'una defensa de Rafael Jiménez de Parga, l'amnistia i va demanar la meva llibertat. I encara que, òbviament, la dictadura no me la va concedir, jo mai no els ho podré agrair prou.

Aquell curs $74-75$ va ser especialment actiu en la pugna per aconseguir les llibertats. Es va fer l'homenatge a Pere Bosh Gimpera, rector de l'antiga Universitat Autonoma, la d'abans de la guerra; Raimon va fer un recital al campus de Bellaterra, després de cinc anys d'absència. El febrer va començar una vaga general que va durar fins a finals de curs, o sigui sis mesos, que és molt temps per mantenir una vaga, i en arribar el juny, fou necessari l'aprovat general. En aquell moment que encara era recent la "Revolució dels Clavells", del campus de Bellaterra alguns en deien "el petit Portugal", no en va, l'abril es va celebrar al campus el primer aniversari de la revolució portuguesa...

En resum, per als qui durant la dictadura vam arribar a la UAB, la universitat no era una campana pneumàtica, sinó tot al contrari, era la punta de Ilança de la lluita per recuperar les llibertats i construir una societat millor, més liture i més justa, i aquella tasca diària de molts universitaris compromesos, militants dels partits democràtics clandestins, feia que Bellaterra cada dia bulís en un entusiasme compartit per professors i alumnes, administratius i laborants... 